\title{
Rancang Bangun Aplikasi Informasi Biaya Produksi Berbasis Web Di PT.Bimasakti Karya Prima
}

\author{
Sri Rahayu' ${ }^{1}$, Irma Kurnia Juliany*2 ${ }^{2}$, Duwi Lailatul Juniar ${ }^{3}$ \\ ${ }^{1}$ Program Studi Teknik Informatika Universitas Raharja, ${ }^{2,3}$ Program Studi Sistem Informasi \\ Universitas Raharja \\ Email : ${ }^{1}$ srirahayu@ raharja.info, *2irma.kurnia@raharja.info, ${ }^{3}$ duwi.lailatul@ raharja.info
}

\begin{abstract}
Abstrak
PT.Bimasakti Karya Prima merupakan sebuah perusahaan yang bergerak di bidang manufaktur dengan memproduksi sepatu "FANS Indonesia". Produksi merupakan proses mengubah bahan baku menjadi barang jadi dan menambah nilai dari suatu produk. Perusahaan harus mempunyai informasi total biaya yang diperlukan saat akan melakukan produksi di setiap periodenya. Namun sistem yang berjalan saat ini belum sepenuhnya dapat membantu. Dikarenakan pembuatan Consumption Sheet pada proses perincian material dan proses Costing sepatu berada pada dua perangkat dengan sistem operasi yang berbeda. Sehingga, diperlukannya pengetikkan ulang data-data pada Consumption Sheet dalam melakukan proses Costing. Ketidaktersedianya database mempersulit dalam melakukan perbaruan data dan perlu mengganti satu persatu di tiap sheet-nya. Tujuan dari penelitian ini yaitu merancang Aplikasi Informasi Biaya Produksi berbasis web, membuat database sesuai dengan kebutuhan perusahaan yang akan mempermudah dalam pengelolaan data biaya produksi serta mengintegrasikan sistem. Metode penelitian yang digunakan ialah metode pengumpulan data dengan melakukan observasi, wawancara dan studi pustaka. Hasil yang didapat dari penelitian ini adalah sebuah sistem aplikasi informasi biaya yang membantu perusahaan dalam mengelola data-data. Mulai dari penentuan spesifikasi komponen dan material produksi sepatu hingga sampai ke proses Costing.
\end{abstract}

Kata kunci : Biaya Produksi, Sepatu, Website

\begin{abstract}
PT.Bimasakti Karya Prima is a company engaged in manufacturing by producing "FANS Indonesia" shoes. Production is the process of converting raw materials to finished goods and adding value to a product. However, the current system is not yet fully able to help, because the making of the Consumption Sheet in the process of material detailing and the Costing process of shoes are on two devices with different operating systems, so the need to re-type the data on the Consumption Sheet in the costing process. The lack of available databases makes it difficult to update data and needs to replace one by one on each sheet. The purpose of this research is to design a web-based Production Cost Information Application, create a database in accordance with company needs that will facilitate data management production costs as well as integrating systems. The research method used is the method of data collection by observing, interviewing and studying literature. The results obtained from this study are a cost information application system that helps companies manage data. Starting from determining the specifications of components and materials for the production of shoes to the costing process.
\end{abstract}

Keywords: Cost Production, Shoes, Website

\section{PENDAHULUAN}

Teknologi sistem informasi merupakan salah satu teknologi yang berkembang pesat saat ini.Berbagai perusahaan yang bergerak dalam berbagai bidang pasti memerlukan sistem informasi untuk membantu kelancaran kegiatan operasionalnya dan membantu dalam 
pengambilan keputusan untuk menentukan strategi perusahaan selanjutnya. PT.Bimasakti Karya Prima merupakan perusahaan manufaktur yang memproduksi sepatu dengan brand Sepatu FANS, dengan banyak keunggulan dan harganya yang cukup terjangkau oleh kalangan masyarakat Indonesia. Mereka mengolah bahan baku menjadi produk jadi. Pada proses produksi tentunya terdapat biaya-biaya yang dikeluarkan, dan perusahaan tentu perlu mempunyai informasi berapa banyak biaya yang perlu dikeluarkan saat akan melakukan produksi perperiodenya.Dalam proses pengolahan data untuk mendapatkan informasi biaya, perusahaan belum sepenuhnya efektif karena masih menggunakan Libreoffice spreadsheet (pengolah angka), juga belum mempunyai database yang terintegrasi. Ini menyebabkan pembaruan harga terbaru ataupun revisi suatu data, masih perlu mengganti di tiap sheet-nya dan dicetak ulang untuk hasil revisinya.Tentu saja ini memerlukan ketelitian dan memakan cukup waktu dan cukup banyak kertas yang digunakan.

\section{METODE PENELITIAN}

\section{Metode Pengumpulan Data}

1. Observasi

Melakukan pengumpulan data melalui pengamatan dengan cara mendatangi langsung ke bagian terkait di PT.Bimasakti Karya Prima. Dengan cara ini, penulis dapat melihat secara nyata apa saja permasalahan yang terjadi di lapangan.

2. Wawancara

Penulis melakukan penelitian dengan mewawancarai stakeholderdan pegawai lain yang terkait di PT.Bimasakti Karya Prima untuk memperoleh data yang dibutuhkan secara akurat.

3. Studi Pustaka

Melakukan studi pustaka dengan cara mengumpulkan, membaca, serta memahami informasidari segala media yang berhubungan dengan permasalahan yang sedang dibahas dalam penelitian ini.

\section{Metode Analisa}

Metode analisis yang dilakukan penulis yaitu menggunakan analisis PIECES (Performance, Information, Economic, Control, Efficiency, Service).Metode PIECES ini berguna untuk mengoreksi sistem informasi yang ada.Sebagai analisis dasar untuk memperoleh pokok-pokok permasalahan yang lebih terperinci lagi.

\section{Metode Perancangan}

Menurut Law (2015) di dalam bukunya menjelaskan, "Unified Modeling Language (UML) adalah bahasa yang dirancang sebagai standar untuk visualisasi sistem perangkat lunak.UML merupakan karya dari Grady Booch, Ivar Jacobson, dan James Rumbaugh.Pada tahun 1997 UML diadopsi sebagai standar oleh Object Management Group (OMG), lalu diajukan ke lembaga standarisasi internasional (ISO) pada tahun 2000.”

\section{LITERATURE REVIEW}

Menurut Azizah, Rahayu dan Nova dalam Jurnal SENSI Vol. 3 No. 2 (2017: 185)“ literature adalah kesusastraan atau kepustakaan, sedangkan review adalah suatu tindakan meninjau, memeriksa kembali suatu hal yang telah dikerjakan sebelumnya sehingga dalam literature review dapat disimpulkan sebagai suatu tindakan memeriksa dan meninjau kembali suatu kepustakaan."

1. Penelitian yang dilakukan oleh Hapsari Rinci K, Azinar Azmuri W, dan Sugiyanto dalam Jurnal Nasional Teknologi Terapan Vol. 2 No. 1. Dengan judul "Rancang Bangun Sistem Produksi dan Persediaan UMKM" (Mei 2018). Sistem berfungsi untuk penentuan HPP dan juga sebagai kontrol proses produksi seperti: mampu melakukan perubahan stok barang otomatis tiap terjadi transaksi, monitoring persediaan terpantau dengan cepat. Juga 
membantu bagian gudang dan produksi dlam membuat laporan yang dibutuhkan. Metode penelitian dengan pengumpulan data seperti observasi, wawancara, dan studi literatur. Analisa kebutuhan dengan Method View Controller. Desain sistem dengan diagram UML.

2. Penelitian yang dilakukan oleh Euis Sitinur, Padeli, dan Sumasih dalam Jurnal SENSI Vol. 2 No. 2. Dengan judul "Penerapan Activity Based Costing System Dalam Laporan Keuangan Untuk Mempermudah Pengendalian Biaya" (Agustus 2016). Laporan keuangan yang mampu menampilkan informasi yang terinci dari pendapatan dan biaya overhead yang digunakan pada proses produksi setiap item yang meliputi proses dari bahan baku sampai menjadi bahan jadi siap jual, sehingga mudah mengetahui kemampuan laba yang dihasilkan dari setiap item yang diproduksi tersebut. Metode Activity Based Costing system. Metode penelitian yang digunakan yaitu analisis SWOT guna mengetahui kekuatan, kelemahan, peluang dan ancaman perusahaan dari segi internal dan eksternal dan strategi perusahaan.

3. Penelitian yang dilakukan oleh Anita B., W. dan Andrian W dalam Jurnal CERITA Vol. 4 No. 2. Dengan judul "Rancang Bangun Sistem Informasi Rencana Anggaran Biaya (RAB) Perusahaan Berbasis Web Pada PT Bumitangerang Mesindotama" (Agustus 2018). Menghasilkan Sistem yang menggunakan input berbasis web dalam proses pengisian kegiatan proyek, rincian bahan yang diperlukan dan perencanaan anggaran biaya yang dibutuhkan sehingga dapat menghasilkan laporan akhir dalam bentuk rekapan yang rapi. Dalam penelitian ini peneliti menggunakan metode System Development Life Cycle (SDLC) yang didukung dari pengumpulan data melalui observasi dan studi pustaka.

\section{HASIL DAN PEMBAHASAN}

Dalam perancangan sebuah program aplikasi informasi biaya produksi berbasis web, dapat digambarkan keseluruhan prosedur yang diperlukan dalam beberapa tahapan analisa sebagai bentuk pengumpulan informasi dalam membangun suatu model yang sesuai dengan kebutuhan dan mampu memberikan solusi yang efektif dan efisien. Beberapa tahapan Rancangan sistem ini menggunakan Visual Paradigm for UML 13.0, salah satu nya menggambarkan use case diagram, activity diagram.

\section{Use Case Diagram Diusulkan}

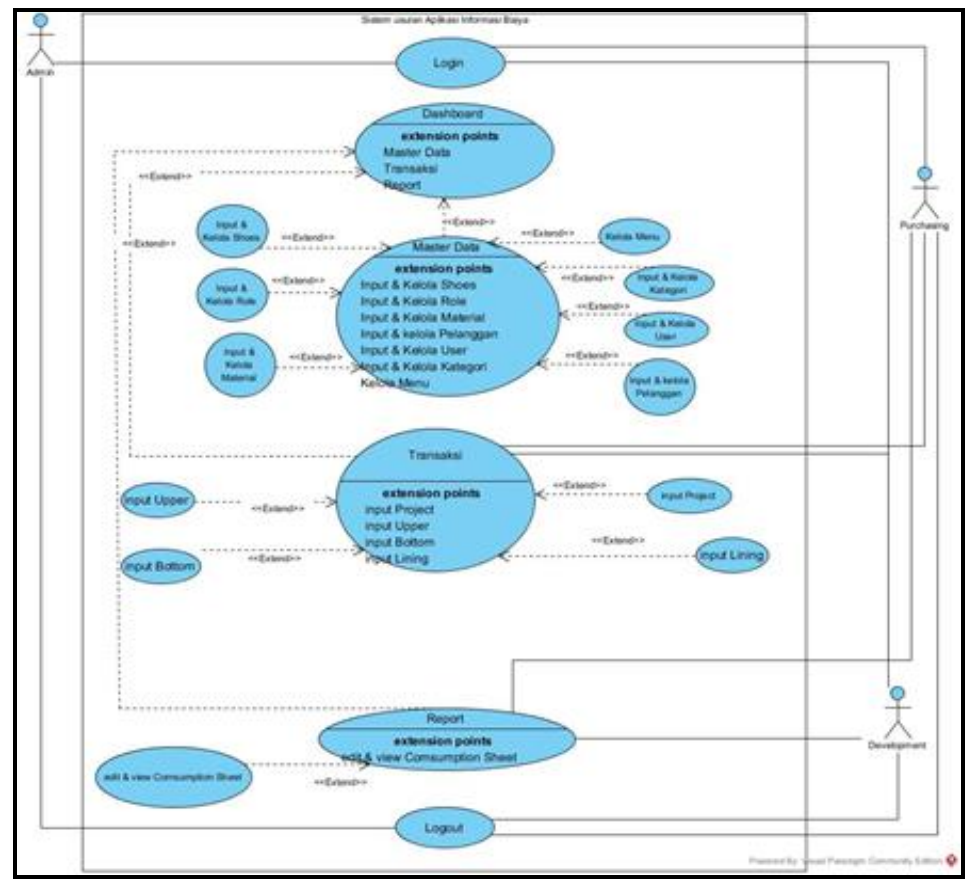

Gambar 1. Use Case Diagram Diusulkan 
Berdasarkan use case diagram diatas, dapat dijelaskan:

a. Sistem boundary yang menggambarkan keseluruhan kegiatan dalam sistem informasi biaya usulan.

b. Terdapat 3 aktor yaitu Admin, Development, dan Purchasing.

c. Use case yang tergambar terdapat 18 usecase.

d. Terdapat 4 include yaitu: Dashboard, Master Data, Transaksi dan Report.

\section{Activity Diagram Diusulkan}

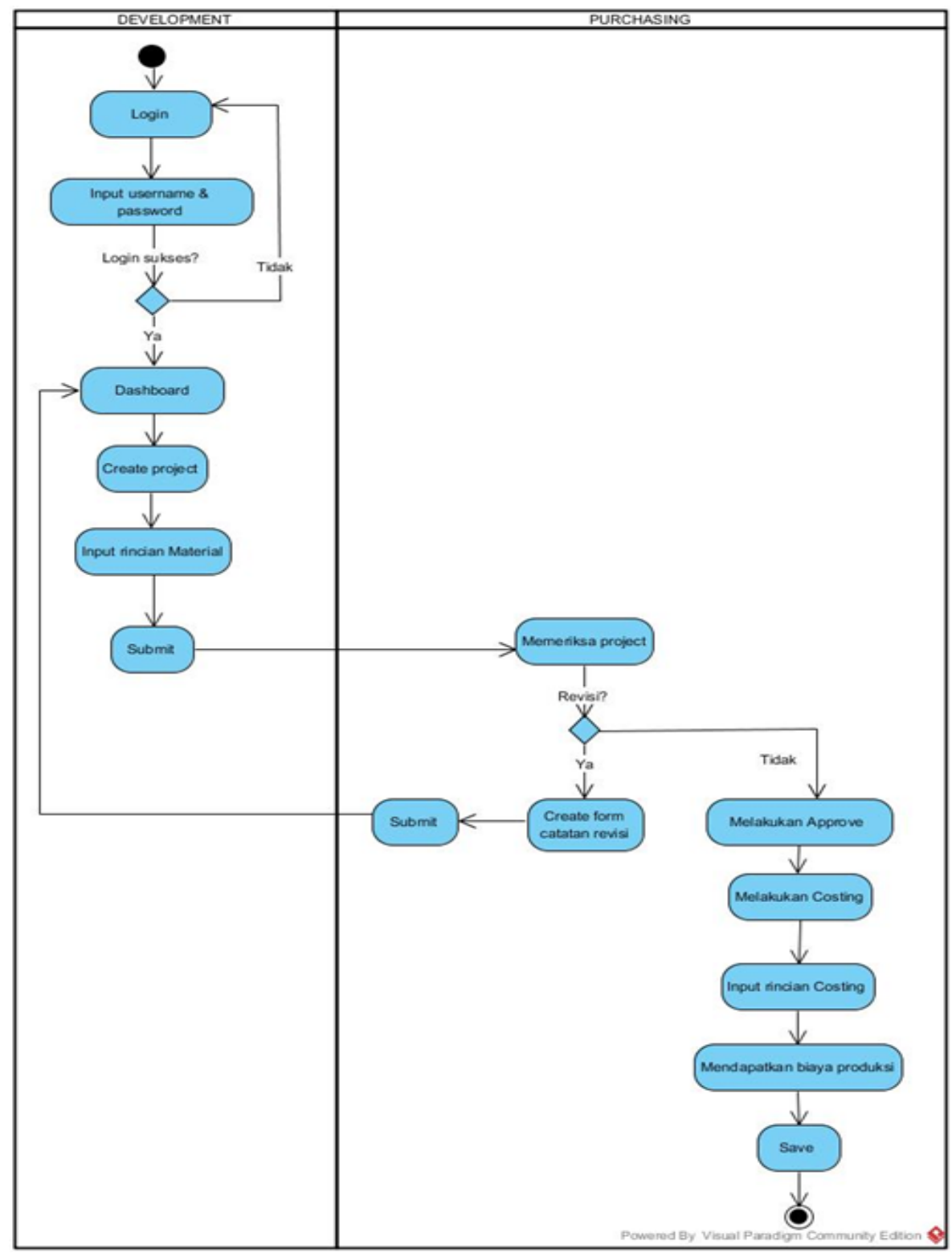

Gambar 2. Activity Diagran Projek Diusulkan

Berdasarkan Activity Diagram Project tersebut, terdapat:

a. 1 initial node, merupakan node yang mengawali kegiatan.

b. 14 action state dari sistem. Yang mencerminkan eksekusi dari suatu aksi yang ada.

c. 2 decision node, node yang menunjukkan pilihan untuk suatu kondisi tertentu, yang menghasilkan hanyaa satu kemungkinan.

d. 1 final node, adalah node yang mengakhiri keseluruhan kegiatan. 
Tabel 1. Perbedaan Sistem Berjalan dan Sistem Usulan

\begin{tabular}{|l|l|l|}
\hline No & \multicolumn{1}{|c|}{ Sistem Berjalan } & \multicolumn{1}{|c|}{ Sistem usulan } \\
\hline 1 & $\begin{array}{l}\text { Dalam memperbarui atau melakukan revisi } \\
\text { rincian data, memerlukan usaha lebih. } \\
\text { Karena perlu menganti di tiap sheet-nya } \\
\text { satu persatu yang pastinya memakan waktu } \\
\text { yang cukup lama. }\end{array}$ & $\begin{array}{l}\text { Penelusuran dan kelola data-data bahan } \\
\text { baku dapat dilakukan secara cepat dan } \\
\text { mudah dengan adanya database. Sehingga, } \\
\text { proses revisi kesalahan data ataupun } \\
\text { perbarui menjadi lebih cepat. Begitupun } \\
\text { dalam pencarian data. }\end{array}$ \\
\hline 2 & $\begin{array}{l}\text { Proses pembuatan Consumption Sheet } \\
\text { dilakukan di dua perangkat yang berbeda } \\
\text { Operating System. Sehingga, perlu } \\
\text { pengetikkan ulang data-data pada } \\
\text { Consumption Sheet agar dapat melakukan } \\
\text { costing dan penentuan biaya produksi } \\
\text { sepasang sepatu. }\end{array}$ & $\begin{array}{l}\text { Dibangun Sistem Informasi yang } \\
\text { terintegrasi untuk keseluruhan proses } \\
\text { pembuatan Consumption Sheet, sampai } \\
\text { mendapatkan total biaya produksi sepasang } \\
\text { sepatu. }\end{array}$ \\
\hline 3 & $\begin{array}{l}\text { Sistem saat ini belum dapat otomatis untuk } \\
\text { mengetahui biaya produksi sepasang sepatu } \\
\text { tiap model/jenisnya. }\end{array}$ & $\begin{array}{l}\text { Dapat langsung diketahui melalui fitur yang } \\
\text { ada di sistem ini yang tentunya dapat } \\
\text { dilakukan dengan lebih mudah. }\end{array}$ \\
\hline 4 & $\begin{array}{l}\text { Pengaksesan hanya dilakukan di tempat } \\
\text { dan diwaktu kerja/kantor. Untuk meminta } \\
\text { konfirmasi/approval perlu bertemu } \\
\text { langsung. }\end{array}$ & $\begin{array}{l}\text { Dengan sistem yang online berbasis } \\
\text { web, user dapat membuat, mengedit, meng- } \\
\text { update, bahkan memeriksa projek dimana } \\
\text { saja } \\
\text { Konfirmasi/approval pun dapat dilakukan } \\
\text { dimana saja dengan mudah, tidak perlu } \\
\text { bertatap muka. }\end{array}$ \\
\hline
\end{tabular}

1. Tampilan Halaman Login

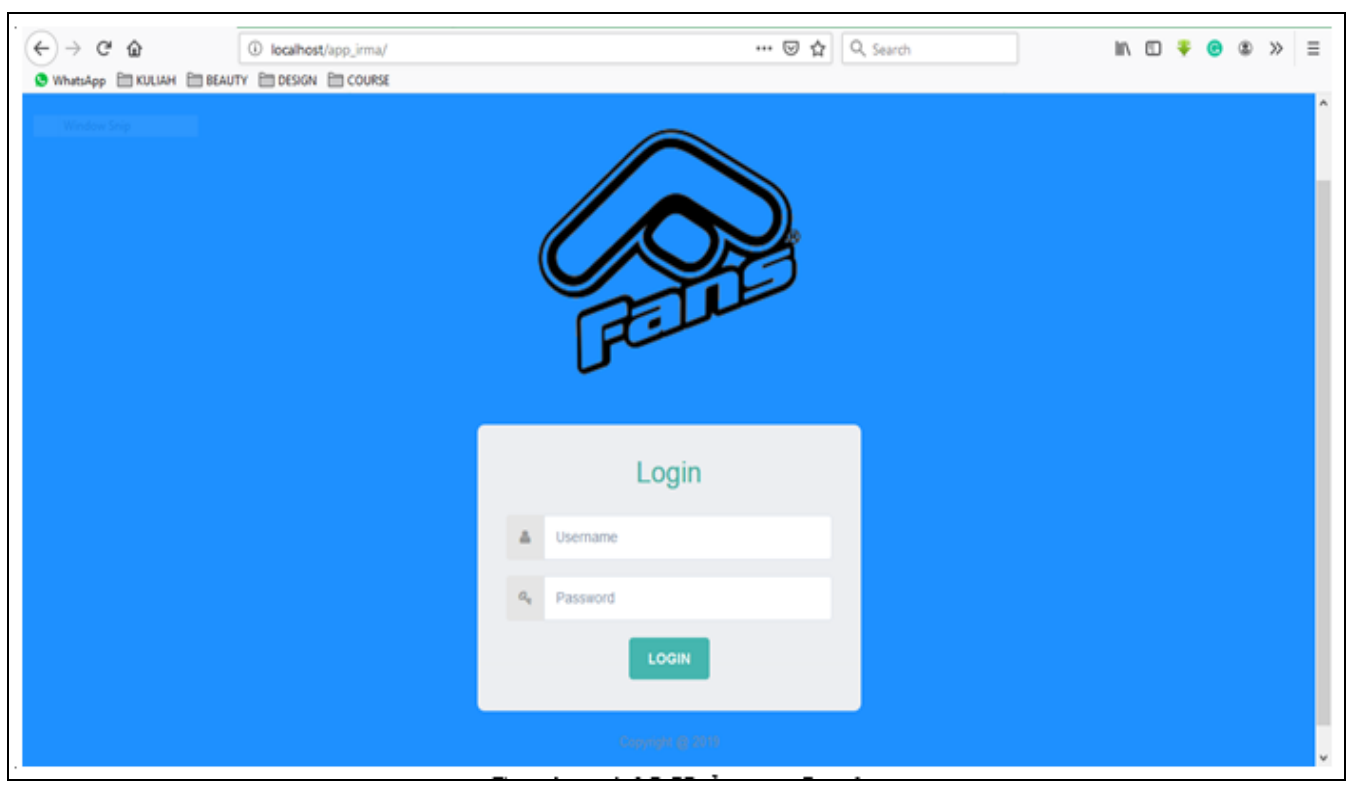

Gambar 3. Halaman Login 
Gambar 3 merupakan tampilan awal sebelum masuk kedalam sistem, user harus melakukan login terlebih dahulu dengan memasukan username dan password yang telah didaftarkan agar dapat masuk kedalam sistem.

2. Tampilan Halaman Project

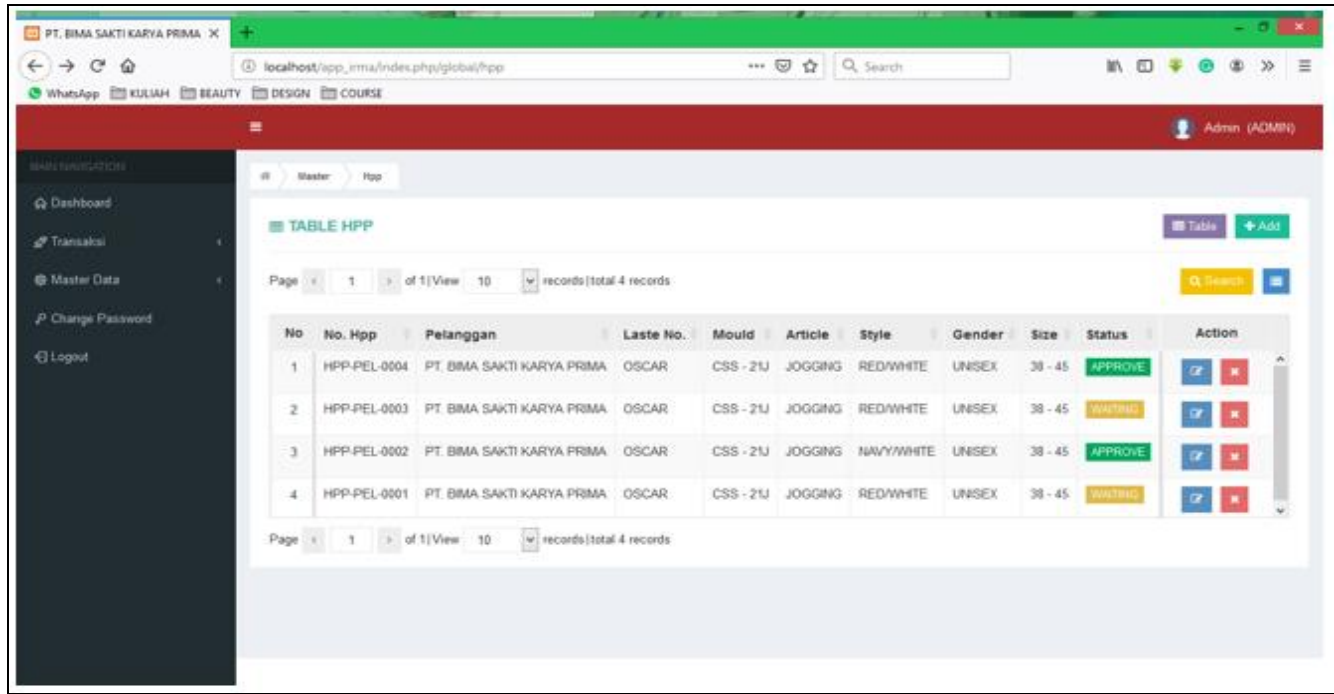

Gambar 4. Halaman Project

Gambar 4 merupakan tampilan halaman transaksi untuk membuat project. Di dalamnya terdapat data-data yang telah di-input sebelumnya. Dapat di-edit dan juga dihapus. Dapat juga di-export dalam bentuk dokumen jika diperlukan.

3. Tampilan Halaman Tambah Data Project

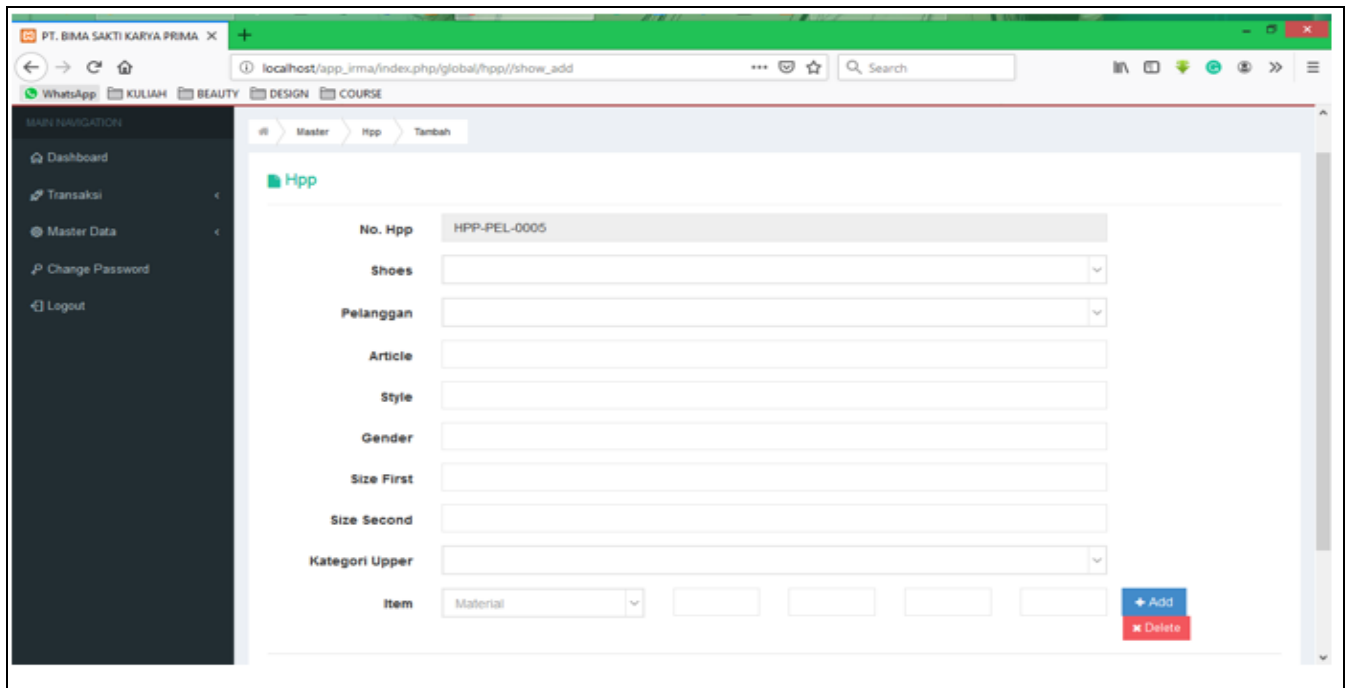

Gambar 5. Halaman Tambah data Project

Gambar 5 merupakan tampilan halaman tambah data untuk Master data Pelanggan. Dimana berisi User dapat melakukan tambah data melalui form yang disediakan. 
4.

Tampilan Halaman Master Data Kategori

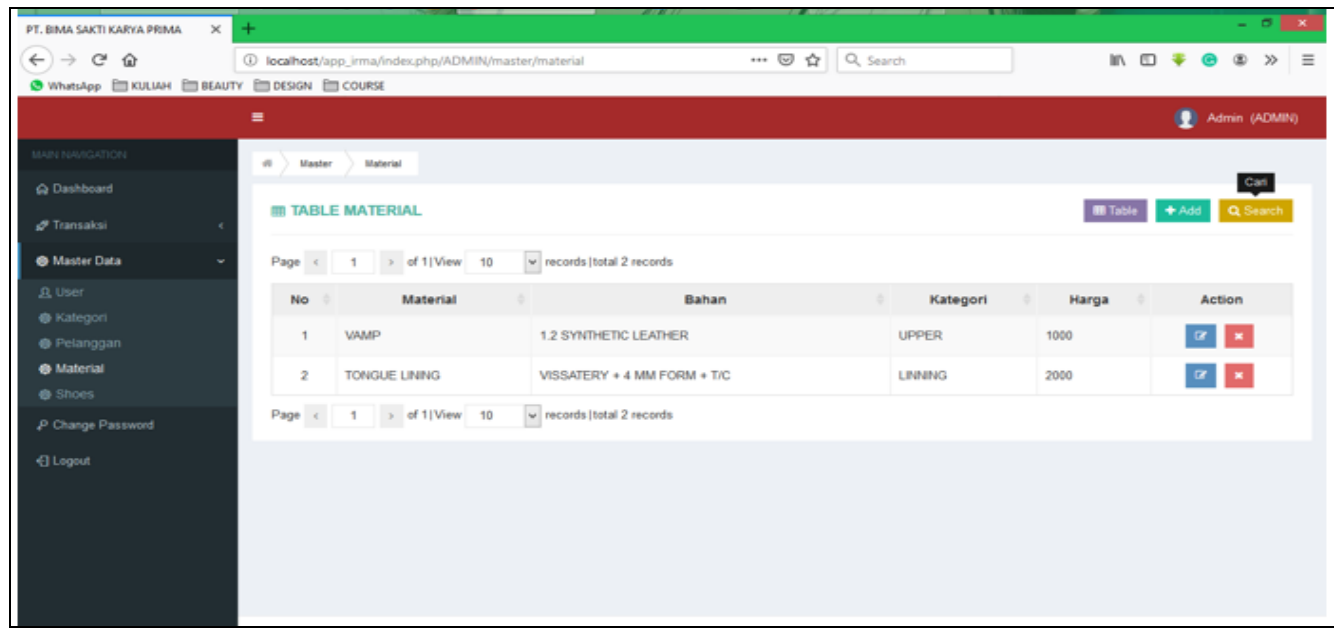

Gambar 6. Halaman Master Data Kategori

Gambar 6 merupakan tampilan halaman Master data untuk data Material. Dimana berisi User dapat melihat isi dari data dan dapat menambah sekaligus mengedit data tersebut.

5. Tampilan Halaman Tambah Data Master Kategori

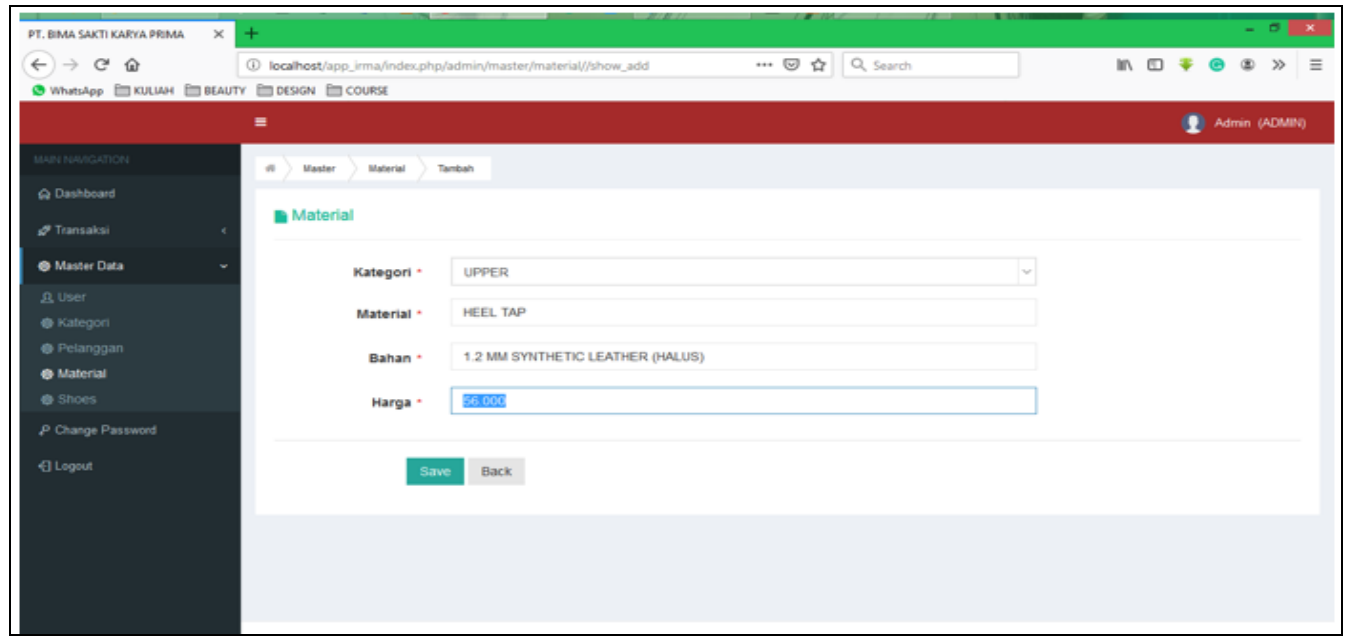

Gambar 7. Tambah data Master Kategori

Gambar 7 merupakan tampilan halaman tambah data untuk Master data Kategori. Dimana berisi User dapat melakukan tambah data melalui form yang disediakan. 
6.

Tampilan Halaman Master Data Pelanggan

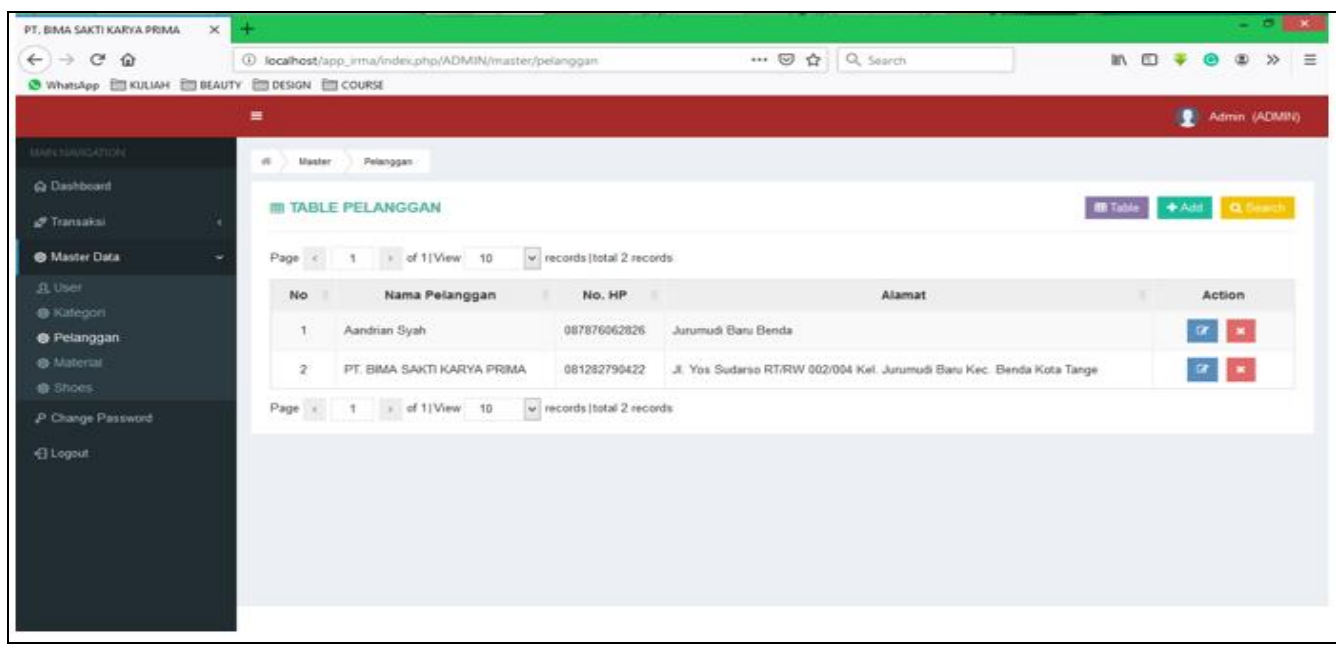

Gambar 8. Halaman Master data Pelanggan

Gambar 8 merupakan tampilan halaman Master data untuk data Pelanggan. Dimana berisi User dapat melihat isi dari data tersebut.Dan dapat menambah sekaligus mengedit data tersebut.

7. Tampilan Halaman Tambah Data Master Pelanggan

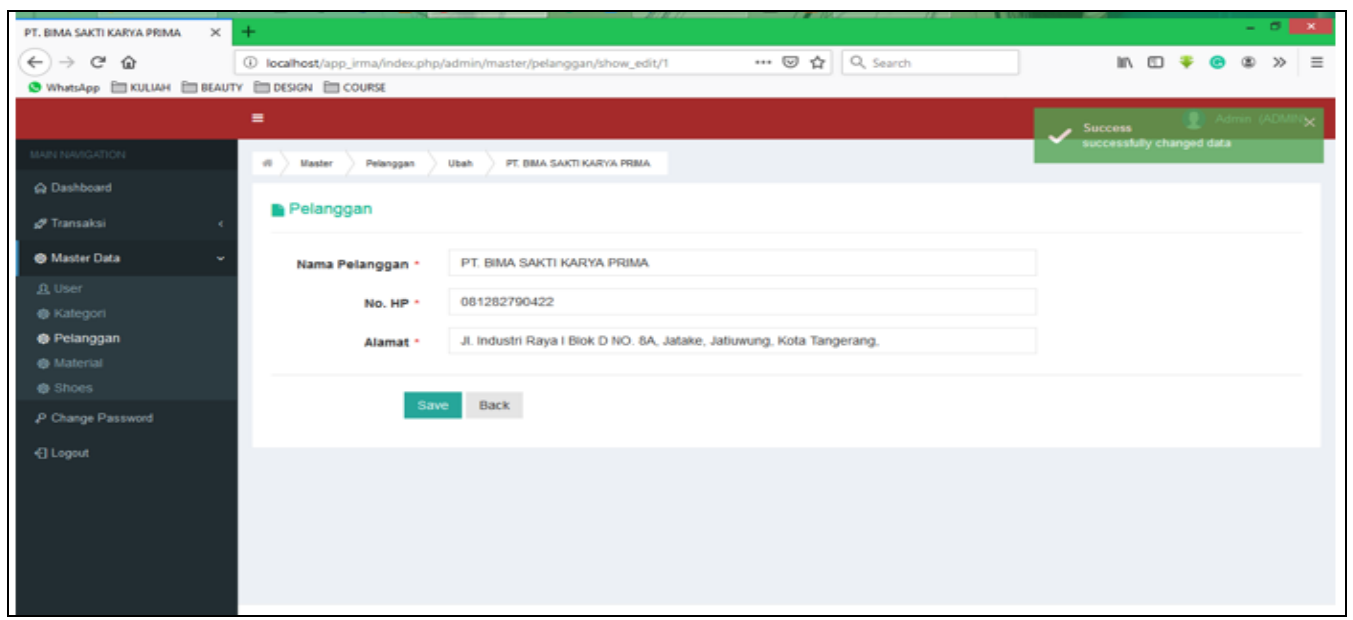

Gambar 9. Halaman Tambah Data Master Pelanggan

Gambar 9 merupakan tampilan halaman tambah data untuk Master data Pelanggan. Dimana berisi User dapat melakukan tambah data melalui form yang disediakan. 
8.

Tampilan Halaman Master Data Material

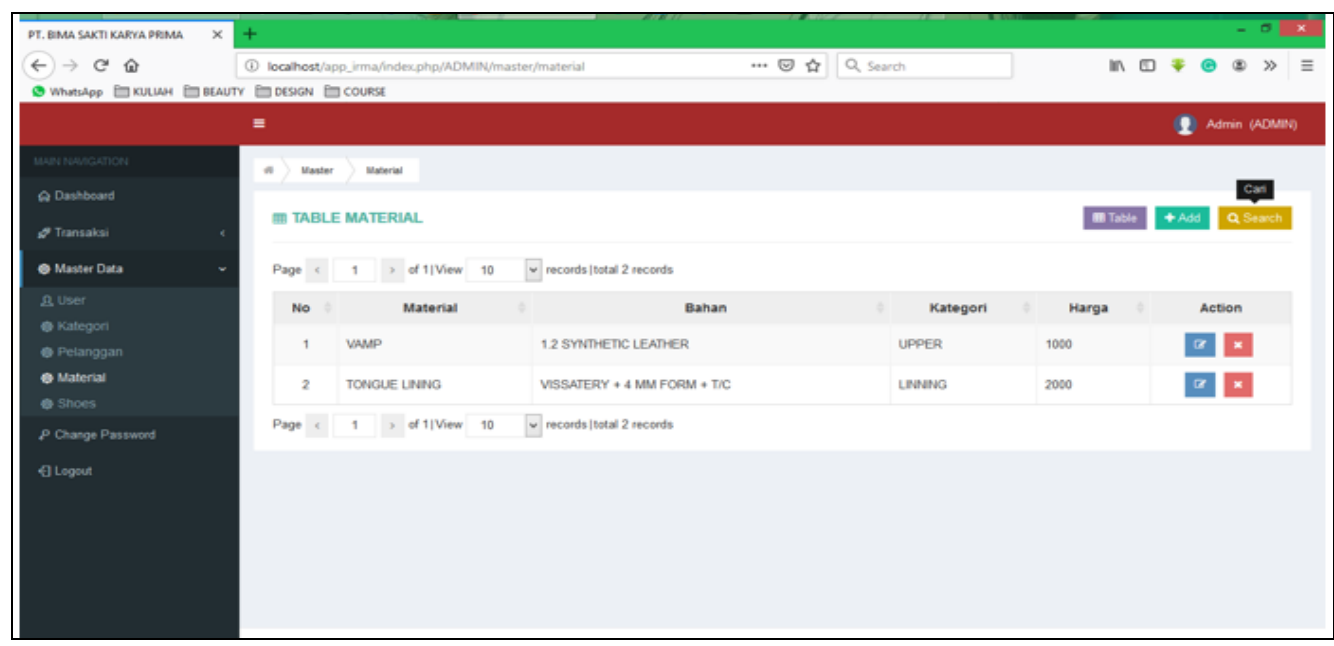

Gambar 10. Halaman Master Data Material

Gambar 10 merupakan tampilan halaman Master data untuk data Material. Dimana berisi User dapat melihat isi dari data tersebut.Dan dapat menambah sekaligus mengedit data tersebut.

9. Tampilan Halaman Tambah Data Master Material

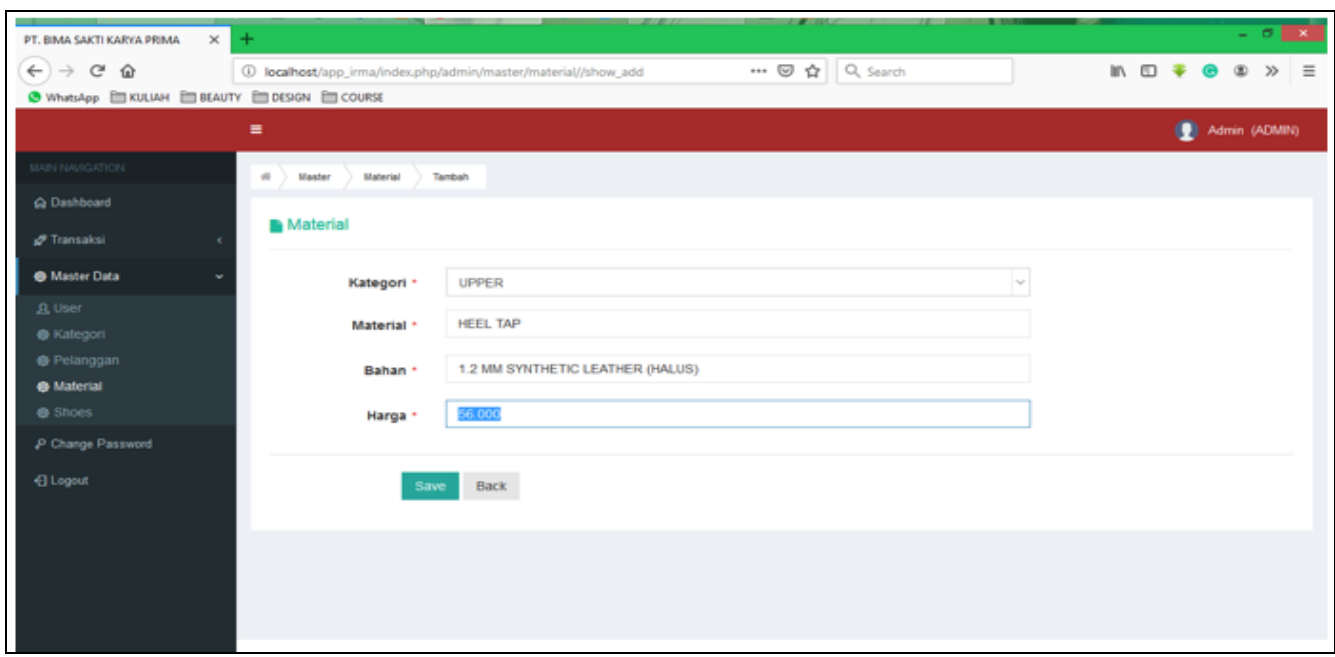

Gambar 11. Halaman Tambah Data Master Material

Gambar 11 merupakan tampilan halaman tambah data untuk Master data Material. Dimana berisi User dapat melakukan tambah data melalui form yang disediakan.

\section{KESIMPULAN}

Berdasarkan hasil analisa penelitian yang sudah diuraikan pada tiap bab sebelumnya serta, berdasarkan hasil pengamatan dari perumusan masalah mengenai Perancangan Aplikasi Informasi Biaya Produksi berbasis Web pada PT.Bimasakti Karya Prima, maka dapat diambil kesimpulan dari rumusan masalah sebagai berikut : 
1. Sistem yang saat ini berjalan masih belum optimal dalam membantu perusahaan mendapatkan informasi biaya produksi. Dikarenakan pembuatan Consumption Sheet mulai dari proses perincian material sepatu hingga proses costing berada pada dua perangkat dengan sistem operasi yang berbeda. Sehingga, diperlukannya pengetikkan ulang data-data agar dapat melakukan costing. Untuk melakukan pembaruan atau merevisi data perlu mengganti satu persatu di tiap sheet-nya terlebih dahulu dan belum otomatis dalam perhitungan kebutuhan biaya produksi.

2. Aplikasi informasi biaya produksi ini dirancang dengan mengumpulkan informasi yang diperlukan, mewawancarai user akan kebutuhan sistem, merancang database, membuat prototipe sistem, melakukan pemrograman menggunakan HTML, CSS, Javascript untuk bagian front-end-nya. Lalu menggunakan PHP Framework CodeIgniter dan database MySQL untuk bagian back-end-nya. Editornya menggunakan Sublime text 3 dan sistem diprogram agar dapat diakses melalui internet browser (online). Dan dibuat agar user dapat dengan cepat juga otomatis untuk mengetahui biaya produksi. Terakhir, melakukan testing untuk memastikan program berjalan sesuai keinginan.

3. Perancangan sistem aplikasi informasi biaya produksi dapat membantu kegiatan operasional di perusahaan menjadi lebih efisien dan optimal. Dikarenakan, sistem yang dibuat berbasis online sehingga mudah diakses dimana saja. Proses yang lebih cepat, tidak perlu manual lagi dalam pengerjaannya. Sistem ini memiliki fungsi create project untuk melakukan input rincian material hingga proses costing. Serta memiliki fitur approval. Laporan atau output yang dihasilkan dapat di-export dalam format dokumen.

\section{SARAN}

Adapun saran-saran dari peneliti untuk lebih meningkatkan kegiatan operasional dalam mendapatkan informasi biaya produksi, yaitu sebagai berikut:

1. Diharapkan dilakukan pengembangan lebih lanjut untuk menyempurnakan sistem yang lebih baik lagi dan meminimalisir kemungkinan terjadinya error atau defect yang dapat merugikan bagi penggunanya.

2. Dilakukan pemeliharaan aplikasi secara berkala. Sehingga, aplikasi ini dapat terus digunakan dan berjalan dengan baik.

\section{DAFTAR PUSTAKA}

[1] Law, Risal. (2015). Mari Belajar Pemrograman Berorientasi Objek menggunakan Visual C\# 6.0.

[2] Azizah, N., Rahayu, S., \& Adhista, N. (2017). Perancangan Sistem Informasi Penilaian Kinerja Karyawan Spg Berstatus Kontrak pada PT. Softex Indonesia Menggunakan Metode Simple Additive Weighting (Saw). Journal Sensi, 3(2), 182-189.

[3] Hapsari, R. K., Azinar, A. W., \& Sugiyanto, S. Rancang Bangun Sistem Produksi dan Persediaan UMKM. Jurnal Nasional Teknologi Terapan (JNTT), 2(1), 81-88.

[4] Aulia, F. U., \& Anam, K. (2015). Penerapan Activity Based Costing System dalam Perhitungan Profitabilitas Produk Pada UD. Niaga Bakti. IQTISHADIA: Jurnal Ekonomi \& Perbankan Syariah, 2(1), 44-62.

[5] Wandanaya, A. B., \& Wicaksono, A. Rancang Bangun Sistem Informasi Rencana Anggaran Biaya (Rab) Perusahaan Berbasis Web pada PT. Bumitangerang Mesindotama. Journal Cerita, 4(2), 110-129. 